\title{
AVALIAÇÃO DA BIOCOMPATIBILIDADE DE VIDRO E VITROCERÂMICA DO SISTEMA SNCP $\left(\mathrm{SiO}_{2}-\mathrm{Na}_{2} \mathrm{O}-\mathrm{CaO}-\mathrm{P}_{2} \mathrm{O}_{5}\right)$
}

Karoline Bastos Mundstock* e Antonio Pedro Novaes de Oliveira

Departamento de Engenharia Mecânica, Universidade Federal de Santa Catarina, CP 476, 88040-900 Florianópolis - SC, Brasil Dachamir Hotza

Departamento de Engenharia Química e de Alimentos, Universidade Federal de Santa Catarina, CP 476, 88040-900 Florianópolis - SC, Brasil

Sizue Ota Rogero

Instituto de Pesquisas Energéticas e Nucleares, Química e Meio Ambiente, Av. Prof. Lineu Prestes, 2242, 05508-000 São Paulo - SP, Brasil

Recebido em 11/2/11; aceito em 13/10/11; publicado na web em 4/1/12

\begin{abstract}
EVALUATION OF THE BIOCOMPATIBILITY OF GLASS AND GLASS CERAMICS OF THE SNCP $\left(\mathrm{SiO}_{2}-\mathrm{Na}_{2} \mathrm{O}-\mathrm{CaO}-\mathrm{P}_{2} \mathrm{O}_{5}\right)$ SYSTEM. This article reports research results related to bioactivity and cytotoxicity tests using neutral red uptake method for glass powders and bulk glass ceramics belonging to the $\mathrm{SNCP}\left(\mathrm{SiO}_{2}-\mathrm{Na}_{2} \mathrm{O}-\mathrm{CaO}-\mathrm{P}_{2} \mathrm{O}_{5}\right)$ system. The obtained materials showed bioactivity when immersed in SBF promoting the surface deposition of HAp. When analyzed as powders, cytotoxicity was evidenced in the processed materials but not when bulk samples were tested.
\end{abstract}

Keywords: glass ceramics; simulated body fluid; cytotoxicity assay.

\section{INTRODUÇÃO}

Os biovidros representam uma classe importante de biomateriais que podem ser utilizados para reconstruir partes, preencher cavidades ou substituir elementos perdidos por doenças ou traumas. ${ }^{1}$ Os primeiros biovidros produzidos, desenvolvidos por L. L. Hench em 1969, foram denominados Bioglass ${ }^{\circledR}$ com composição $45 \mathrm{SiO}_{2} \cdot 6 \mathrm{P}_{2} \mathrm{O}_{5} \cdot 24,5 \mathrm{Na}_{2} \mathrm{O} .24,5 \mathrm{CaO}$. O Bioglass ${ }^{\circledR}$ é altamente bioativo e ainda hoje é muito utilizado, entretanto, sua aplicação é limitada devido a sua baixa taxa de reabsorção e baixa resistência mecânica. ${ }^{2,3}$ Com o intuito de melhorar as propriedades do Bioglass ${ }^{\circledR}$ diversas pesquisas têm sido realizadas e várias vitrocerâmicas bioativas (obtidas por cristalização controlada de vidros) foram desenvolvidas, tais como o Bioverit I $\left(\mathrm{SiO}_{2}-\mathrm{Al}_{2} \mathrm{O}_{3}-\mathrm{MgO}-\mathrm{CaO}-\mathrm{P}_{2} \mathrm{O}_{5}\right)$, o Cerabone (MgO$\left.-\mathrm{CaO}-\mathrm{SiO}-\mathrm{P}_{2} \mathrm{O}_{5}-\mathrm{CaF}_{2}\right)$ e o Ceravital $\left(\mathrm{Na}_{2} \mathrm{O}-\mathrm{K}_{2} \mathrm{O}-\mathrm{MgO}-\mathrm{CaO}-\mathrm{SiO}_{2}\right.$ $-\mathrm{P}_{2} \mathrm{O}_{5}$ ). A diferença de composição química entre os vidros resulta em modificações nas propriedades físicas e químicas bem como na biocompatibilidade e bioatividade e nas taxas de degradação e de reabsorção. Tais características permitem a seleção e a especificação de biovidros com propriedades adequadas para uma dada aplicação em uma região específica. ${ }^{2,4}$

O êxito da aplicação de um material no organismo depende primeiramente de sua biocompatibilidade, ou seja, depende da habilidade do material desempenhar uma função específica no organismo sem provocar efeitos tóxicos ou danosos aos sistemas biológicos. ${ }^{4} \mathrm{Um}$ material biocompatível pode ser bioinerte ou bioativo, dependendo de sua resposta biológica na interface tecido/material. Se o material é bioativo, após a sua implantação ocorre a formação de uma camada de HAp (hidroxiapatita) em sua superfície e esta camada promove uma forte ligação entre o material e o tecido ósseo. ${ }^{5,6}$

Para verificar a bioatividade do material, são realizados ensaios em SBF (Simulated Body Fluid, fluido corpóreo simulado). Quanto maior a bioatividade menor é o tempo para que ocorra a interação e adesão entre o implante e o tecido ósseo, maior a força de adesão

\footnotetext{
*e-mail: mundstock@yahoo.com.br
}

entre eles, a espessura da zona de adesão e as forças mecânicas aumentam e melhor é o desempenho do biomaterial. ${ }^{4}$ A bioatividade é muito importante quando o material é empregado na forma de partículas, pois ocorre uma boa coesão entre as partículas evitando sua migração através do sistema linfático. ${ }^{7,8}$ A migração pode ocorrer quando o diâmetro das partículas é menor que $90 \mu \mathrm{m}$. Portanto, o material na forma de partículas geralmente é utilizado quando se pretende reparar um pequeno defeito ósseo, pois o material pode ser facilmente adaptado ao formato da falha. Os primeiros estudos de bioatividade realizados por Hench et al. ${ }^{4}$ mostraram que todo vidro que liberava íons de cálcio e fósforo; quando imersos em uma solução de água destilada tamponada com tris-hidroximetil-amino-metano e ácido clorídrico em $\mathrm{pH} 7,25$ a $37^{\circ} \mathrm{C}$, promoviam a formação de uma camada de HAp. No entanto, essa afirmativa nem sempre foi válida, pois vidros que não liberavam cálcio e fósforo quando imersos nesta solução e não promoviam o aparecimento da camada de HAp, apresentavam bioatividade quando submetidos a teste in vivo. ${ }^{9,10}$

Em 1990, Kokubo e seus colaboradores desenvolveram uma nova solução denominada fluido corpóreo simulado (SBF) com composição química e $\mathrm{pH}$ próximos ao plasma sanguíneo para testar a bioatividade de materiais. ${ }^{11}$ Tal solução foi capaz de induzir mudanças estruturais na superfície dos vidros e os resultados de bioatividade mostraram-se semelhantes aos apresentados in vivo. Com este procedimento in vitro foi possível diminuir a necessidade de sacrifício de cobaias. ${ }^{2,11}$ $\mathrm{O}$ teste in vitro de bioatividade consiste em imergir o material a ser testado em solução SBF por um período de $3 \mathrm{~h}$ a 15 dias e verificar a formação de HAp na superfície do material em teste. O grau de bioatividade é classificado de acordo com o tempo necessário para que ocorra o aparecimento da camada de HAp. ${ }^{2}$ Além da solução original de Kokubo existem outras soluções desenvolvidas com a mesma finalidade, como a solução de Ringer e a solução de Tas. O que as difere é a concentração das espécies químicas. ${ }^{12-14}$

É importante salientar que todas as soluções citadas simulam apenas a parte inorgânica do fluido corpóreo e não são adicionados componentes como proteínas, glicose e vitaminas. A diferença dos resultados dos testes realizados in vivo e in vitro pode ser devida a este 
fato. Além disso, a concentração de alguns íons, como $\mathrm{K}^{+}, \mathrm{Ca}^{2+}, \mathrm{Cl}^{-} \mathrm{e}$ $\mathrm{HPO}_{4}^{2-}$, que compõem os fluidos corpóreos, pode variar de acordo com o sexo, a idade e nutrição dos indivíduos. Sabe-se também que cada um desses íons que compõem o SBF desempenha um papel importante durante o processo de formação óssea. ${ }^{6,15}$

Outros fatores também podem alterar os resultados do ensaio in vitro e alguns cuidados devem ser tomados como utilizar um recipiente plástico, com uma superfície lisa e sem ranhuras para não induzir a precipitação de HAp, obtendo um resultado falso positivo. Se o ensaio for feito em meio estático a precipitação da HAp pode ocorrer mais rapidamente. ${ }^{16} \mathrm{O}$ aumento da área específica de superfície do material, a relação material/líquido (SBF) e a presença de contaminantes podem favorecer a precipitação da HAp. De acordo com Bohner e Lemaitre, ${ }^{16}$ a solução deve ser preparada em atmosfera de $\mathrm{CO}_{2}(5 \%)$, ultrafiltrada e armazenada em local protegido da luz. Estudos realizados por Ebisawa et al. ${ }^{17}$ e Ohura et al. ${ }^{18}$ mostram que a formação da $\mathrm{HAp}$ pode ser inibida pela adição de $\mathrm{MgO}, \mathrm{B}_{2} \mathrm{O}_{3}$, $\mathrm{CaF}_{2}, \mathrm{Fe}_{2} \mathrm{O}_{3}$ ou $\mathrm{Al}_{2} \mathrm{O}_{3}$ e favorecida pela adição de $\mathrm{Na}_{2} \mathrm{O}$ ou $\mathrm{P}_{2} \mathrm{O}_{5}$ e pela presença de $\mathrm{SiO}_{2}$ nos vidros. Walsh et al..${ }^{19}$ Apelt et al.${ }^{20} \mathrm{e}$ Ohura et al..$^{18}$ também comentam que o ensaio em SBF deve ser feito com muito cuidado para não fornecer um resultado falso positivo ou falso negativo de bioatividade e além disso sugerem que outras análises devem ser feitas para caracterizar o material.

Um dos ensaios complementares ao ensaio de bioatividade é o ensaio de citotoxicidade, que é o primeiro ensaio in vitro para se avaliar a biocompatibilidade do material (norma ISO 10993). ${ }^{21}$ Este ensaio pode ser utilizado para acompanhar o processo de obtenção de biomateriais e para se fazer eventuais correções caso o material apresente citotoxicidade. Quando o material apresenta leve toxicidade ou não toxicidade, os testes de biocompatibilidade devem prosseguir com ensaios in vivo utilizando animais de laboratório. ${ }^{22}$ Os ensaios de citotoxicidade têm como objetivo detectar se o material é capaz de produzir efeitos letais ao sistema biológico em nível celular e dentre as suas vantagens estão o curto tempo de ensaio e o pequeno número de variáveis experimentais. Outra vantagem é que dados significativos são obtidos mais facilmente e o número de animais de laboratório é reduzido. ${ }^{22,23}$ Nos ensaios in vivo, animais de uma mesma espécie podem apresentar respostas diferentes, devido à predisposição genética do organismo e à resistência individual.

Neste trabalho, os ensaios de citotoxicidade foram realizados seguindo a norma ISO 10993 utilizando o método de incorporação do vermelho neutro. Este método sugere que os extratos dos materiais em teste sejam colocados em contato com uma cultura de células de maneira que, após um determinado tempo, a viabilidade celular é verificada pela medida do corante vital vermelho neutro. ${ }^{21} \mathrm{O}$ corante em contato com as células atravessa a membrana celular fixando-se na matriz lisossomal, corando as células. Quando o material testado é nocivo às células, as mesmas entram em processo de necrose, ocorrendo assim a lesão de sua membrana e, consequentemente, não fixando o corante. O resultado da análise de citotoxicidade é interpretado a partir de uma análise quantitativa do teor do corante vital vermelho neutro na solução ou por meio de medidas do diâmetro do halo de inibição, uma região que aparece ao redor do material que apresenta células descoradas. ${ }^{23}$ Para realizar os testes de citotoxicidade a norma ISO 10993 recomenda ainda o uso de "linhagens de células", que são culturas de células padronizadas que proliferam normalmente em garrafas de cultivo. As linhagens celulares recomendadas pela norma ISO 10993 são: L-929, Balb/c 3T3, MRC-5, WI-38, Vero, BHK-21 e V-79 da ATCC (American Type Culture Collection). ${ }^{23,24}$ Neste trabalho, optou-se pela linhagem celular NCTC 929 que são células fibroblásticas obtidas do tecido conectivo de camundongos, provenientes da ATCC.

De acordo com Uo et al., ${ }^{25}$ a citotoxicidade dos vidros está re- lacionada à sua taxa de dissolução. Se o material for muito solúvel, pode liberar íons que lesam as células e tornam o material citotóxico. Mas não é só a citotoxicidade que é afetada pela solubilidade do material. Se o material for muito solúvel, pode degradar antes que ocorra qualquer tipo de interação com o tecido que ele deveria substituir. A solubilidade do vidro pode ser adequada ajustando-se as proporções dos modificadores de retículo. A incorporação de íons metálicos com um grande raio iônico e uma baixa carga elétrica aumenta a solubilidade do vidro e pode aumentar a toxicidade do material. Da mesma maneira, a incorporação de íons com pequeno raio iônico e carga elétrica elevada conduz a uma diminuição da velocidade de dissolução do vidro e a uma provável diminuição de sua toxicidade. Com uma maior concentração de $\mathrm{Na}^{+}$no vidro, há um maior consumo de $\mathrm{H}^{+}$da solução, tornando o $\mathrm{pH}$ cada vez mais básico e a basicidade excessiva do meio pode lesionar as células. ${ }^{26}$

Este trabalho reporta resultados sobre os ensaios in vitro de bioatividade em SBF e de citotoxicidade pelo método de incorporação do vermelho neutro do vidro $\mathrm{SNCP}\left(51,3 \mathrm{SiO}_{2} \cdot 26,8 \mathrm{Na}_{2} \mathrm{O} .13,8 \mathrm{CaO} .8,1 \mathrm{P}_{2} \mathrm{O}_{5}\right)$ e de vitrocerâmicas celulares preparadas pelo método da réplica a partir do vidro SNCP, cujo preparo foi apresentado em trabalho anterior. ${ }^{27}$ Como muitos trabalhos indicam que variações nos ensaios podem provocar um resultado falso negativo ou falso positivo, quanto à bioatividade do material, vislumbrou-se a necessidade de reavaliar a bioatividade e biocompatibilidade do biovidro anteriormente estudado e avaliado como citotóxico. Conforme descrito em trabalho anterior o mesmo apresentou características microestruturais que favoreciam sua aplicação como material de implante e foi testado na forma de pó e não na forma de vitrocerâmica celular como será aplicado no organismo. ${ }^{23}$

\section{PARTE EXPERIMENTAL}

O fluido corpóreo simulado (SBF) foi preparado dissolvendo os reagentes em água deionizada na ordem em que são mostrados na Tabela 1, de acordo com a metodologia descrita na norma ISO FDIS 23317. ${ }^{28}$ Após todos os reagentes terem sido dissolvidos, foi feito um ajuste no $\mathrm{pH}$, para que se atingisse o valor 7,25 adicionando $\mathrm{HCl} 0,10$ mol L-1 e tris-hidroximetilaminometano $0,05 \mathrm{~mol} \mathrm{~L}^{-1} \cdot{ }^{29} \mathrm{~A}$ solução foi então filtrada utilizando um papel filtro capaz de reter partículas com dimensões de até $0,25 \mu \mathrm{m}$.

Tabela 1. Composição química do SBF

\begin{tabular}{ccc}
\hline Ordem & Reagentes & Quantidades $(\mathrm{g} / \mathrm{L})$ \\
\hline 1 & $\mathrm{NaCl}$ & 6,547 \\
2 & $\mathrm{NaHCO}_{3}$ & 2,268 \\
3 & $\mathrm{KCl}$ & 0,373 \\
4 & $\mathrm{Na}_{2} \mathrm{HPO}_{4} \cdot 2 \mathrm{H}_{2} \mathrm{O}$ & 0,178 \\
5 & $\mathrm{MgCl}_{2} \cdot 6 \mathrm{H}_{2} \mathrm{O}$ & 0,305 \\
6 & $\mathrm{CaCl}_{2} \cdot 2 \mathrm{H}_{2} \mathrm{O}$ & 0,368 \\
7 & $\mathrm{Na}_{2} \mathrm{SO}_{4}$ & 0,071 \\
8 & $\left(\mathrm{CH}_{2} \mathrm{OH}\right)_{3} \mathrm{CNH}_{2}$ & 6,057 \\
\hline
\end{tabular}

Foram realizados em $\mathrm{SBF}$ ensaios in vitro de bioatividade das amostras do vidro $\mathrm{SNCP}\left(\mathrm{SiO}_{2}-\mathrm{Na}_{2} \mathrm{O}-\mathrm{CaO}-\mathrm{P}_{2} \mathrm{O}_{5}\right)$ e das vitrocerâmicas celulares preparadas pelo método da réplica, cuja preparação foi descrita anteriormente. ${ }^{27}$

As amostras, na forma de cilindros, foram colocadas em frascos de polipropileno contendo $10 \mathrm{~mL}$ de $\mathrm{SBF}$ e foram mantidas durante 15 dias em estufa a $37^{\circ} \mathrm{C}$, simulando a temperatura do corpo humano. Transcorrido o tempo de incubação os cilindros foram submetidos 
à análise microestrutural, em microscópio eletrônico de varredura, MEV (Philips, modelo XL30) e química semiquantitativa por meio de microssonda de energia dispersiva de raios X, EDX acoplada ao MEV.

Para a realização do ensaio de citotoxicidade foi utilizada a linhagem celular NCTC Clone 929 da ATCC, Rockville, MD, EUA. O meio de cultura utilizado foi o MEM (Minimum Essential Medium, meio essencial mínimo) suplementado com $10 \%$ de soro fetal bovino (SFB) da Laborclin, 0,1 mM L ${ }^{-1}$ de aminoácidos não essenciais e 1 $\mathrm{mM} \mathrm{L}^{-1}$ de piruvato de sódio (MEM-uso).

\section{Preparo da microplaca}

A cultura das células em garrafa de cultivo é realizada em meio MEM-uso em estufa úmida (modelo CB150, marca Binder) com 5\% de $\mathrm{CO}_{2}$ a uma temperatura de $37^{\circ} \mathrm{C}$. Após o cultivo foi preparada uma suspensão celular com 5,0 x $10^{5}$ células $/ \mathrm{mL} ; 0,2 \mathrm{~mL}$ desta suspensão foram distribuídas em cada poço de uma microplaca com 96 poços. Essa microplaca foi incubada por $24 \mathrm{~h}$, a $37^{\circ} \mathrm{C}$ em estufa com atmosfera úmida contendo $5 \%$ de $\mathrm{CO}_{2}$, para adesão e formação da monocamada celular.

\section{Extratos das amostras}

Foram utilizadas amostras do vidro SNCP e da vitrocerâmica celular preparada pelo método da réplica tanto na forma de pó (45 $\mu \mathrm{m})$ como na forma sólida. Para amostra na forma de pó os extratos foram preparados adicionando-se $1 \mathrm{~mL}$ de MEM-uso para cada 0,1 $\mathrm{g}$ do material e para amostra na forma sólida com geometria definida foi utilizado $1 \mathrm{~mL}$ de MEM-uso por $\mathrm{cm}^{2}$ de área superficial. Como controle negativo, foi utilizado $\mathrm{Al}_{2} \mathrm{O}_{3}$ em uma concentração de $0,1 \mathrm{~g}$ $\mathrm{mL}^{-1}$ de MEM-uso e como controle positivo, material citotóxico, foi utilizado uma solução de fenol $0,02 \%$. Todos estes extratos foram mantidos em estufa durante $48 \mathrm{~h}$ a $37^{\circ} \mathrm{C}$. Com os extratos obtidos, foram preparadas 5 diluições de 100, 50, 25, 12,5 e 6,25\% dos mesmos, em MEM-uso.

\section{Ensaio propriamente dito}

O meio de cultura da microplaca foi substituído pelas diluições seriadas dos extratos das amostras e dos respectivos controles, em triplicata. Nos poços correspondentes ao controle de células, o meio de cultura foi substituído por MEM-uso. A microplaca foi novamente incubada em estufa úmida com $5 \%$ de $\mathrm{CO}_{2}$ a $37{ }^{\circ} \mathrm{C}$. Após 24 h o extrato foi substituído por uma solução de vermelho neutro (diluição da solução mãe 1:100 em MEM). Solução mãe de vermelho neutro = solução aquosa $5 \mathrm{~g} \mathrm{~L}^{-1}$. Após $3 \mathrm{~h}$ em incubadora a $37^{\circ} \mathrm{C}$ foi verificada a incorporação do vermelho neutro pelas células vivas. $\mathrm{O}$ meio foi removido e as células na microplaca foram lavadas 2 vezes com PBS (Phosphate-Buffered Saline solution) que é uma solução tampão de fosfato com $\mathrm{pH} 7,4$ contendo em cada $1 \mathrm{~L}$ de solução $8 \mathrm{~g}$ de $\mathrm{NaCl}$, $0,2 \mathrm{~g}$ de $\mathrm{KCl}, 1,15 \mathrm{~g}$ de $\mathrm{Na}_{2} \mathrm{HPO}_{4}$ e 0,2 g de $\mathrm{KH}_{2} \mathrm{PO}_{4}$. Em seguida, foi feita outra lavagem com uma solução de $\mathrm{CaCl}_{2}$ em formaldeído ( $1 \%$ de $\mathrm{CaCl}_{2}$ em formaldeído $0,5 \%$ ). Após o descarte da solução de lavagem, cada poço recebeu $0,2 \mathrm{~mL}$ da solução de ácido acético $1 \%$ em etanol (1:1). A microplaca, após ser agitada por $10 \mathrm{~min}$, foi submetida a medidas de densidade óptica em um espectrofotômetro, leitora de ELISA (modelo RC Sunrise da Tecan) com filtro de $540 \mathrm{~nm}$ e filtro de referência de $620 \mathrm{~nm} \cdot{ }^{22}$ A viabilidade celular foi determinada pela Equação 1:

$$
V C(\%)=\left(\frac{\text { DOamostra }}{\text { DOcontrole }}\right) \times 100
$$

onde: $\mathrm{VC}=$ viabilidade celular (porcentagem de células sobreviven- tes em relação ao controle); $\mathrm{DO}_{\text {amostra }}=$ média da densidade óptica das triplicatas de cada diluição dos extratos dos materiais testados; $\mathrm{DO}_{\text {controle }}=$ média da densidade óptica dos poços correspondentes ao controle de células. Com os dados obtidos é possível obter graficamente o índice de citotoxicidade, $\mathrm{IC}_{50 \%}$, de cada amostra. $\mathrm{IC}_{50 \%}$ significa a concentração do extrato que lesa ou mata $50 \%$ da população celular no ensaio de citotoxicidade. ${ }^{22}$

\section{RESULTADOS E DISCUSSÃO}

A micrografia obtida por MEV do vidro SNCP após 15 dias de imersão em SBF é apresentada na Figura 1.

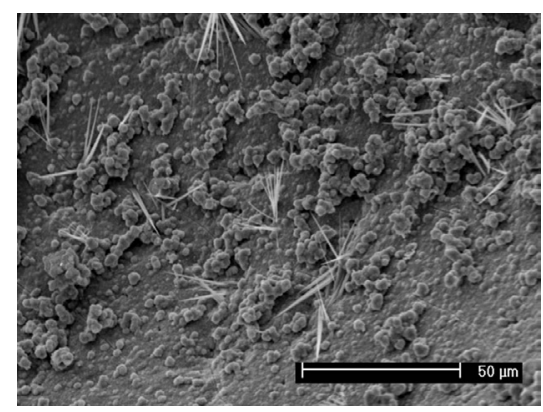

Figura 1. Micrografia (MEV) do vidro SNCP imerso em SBF durante 15 dias

Nessa micrografia é evidente a presença de estruturas na forma de glóbulos que se assemelham à morfologia típica de couve-flor da hidroxiapatita. Este fato foi confirmado através da análise de EDX, que indicou uma relação molar de $\mathrm{Ca} / \mathrm{P}$ igual a 1,66 nestes glóbulos. Esse valor é muito próximo da razão molar $\mathrm{Ca} / \mathrm{P}$ da HAp estequiométrica que é de 1,67.

Há forte evidência de que o vidro SNCP é constituído por um material bioativo, ou seja, capaz de promover a ligação entre o material e o tecido ósseo a partir da formação de uma camada de hidroxiapatita biologicamente ativa na interface material/osso.

As micrografias da Figura 2 são resultantes de observações ao MEV da vitrocerâmica celular preparada com o vidro SNCP pelo método da réplica imersa em SBF durante 7, 14, 21 e 28 dias. O material presente na superfície da amostra também apresentou uma razão $\mathrm{Ca} / \mathrm{P}$ de 1,67 , indicando a presença de HAp e que o material pode ser considerado bioativo. Aparentemente, a vitrocerâmica celular que ficou imersa durante 28 dias em SBF apresenta uma estrutura mais densa, que pode ser resultante de uma maior precipitação de HAp na superfície do material.

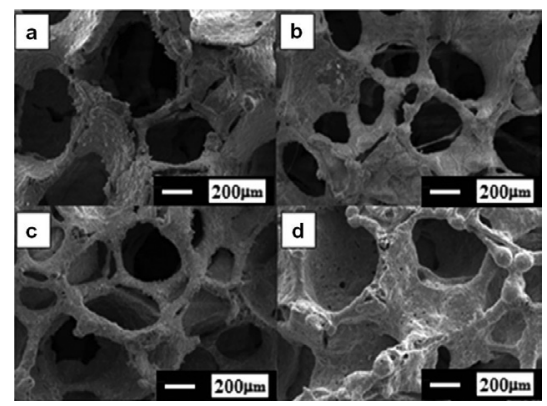

Figura 2. Micrografias (MEV) da vitrocerâmica preparada com o vidro SNCP pelo método da réplica imersa em SBF durante a) 7 dias, b) 14 dias, c) 21 dias e d) 28 dias

$\mathrm{Na}$ avaliação da citotoxicidade dos materiais em estudo, foram calculadas as porcentagens de viabilidade celular (sobrevivência das 
células) em cada diluição do extrato com as medidas de densidade óptica obtidas, em relação a células de controle do ensaio, consideradas como $100 \%$. Projetando-se em gráfico a porcentagem de viabilidade celular em função da concentração do extrato, foram obtidas curvas de viabilidade celular das amostras, assim como dos controles positivo e negativo. A partir do gráfico pode ser obtido o índice de citotoxicidade $\left(\mathrm{IC}_{50}\right)$ dos materiais. Todos os materiais que apresentam curva de viabilidade celular acima da linha do $\mathrm{IC}_{50}$ são considerados não citotóxicos, como o controle negativo e os que apresentam a curva cruzando ou abaixo da linha do $\mathrm{IC}_{50}$ são considerados citotóxicos, como o controle positivo.

A Figura 3 mostra a curva de viabilidade celular do vidro SNCP, na forma de pó. Pode ser verificado que a curva de viabilidade celular está abaixo da linha do $\mathrm{IC}_{50}$ indicando que o vidro $\mathrm{SNCP}$, na forma de pó mostrou-se muito tóxico. O controle positivo, comprovadamente tóxico, apresentou $\mathrm{IC}_{50}$ de 40 , ou seja, o extrato na concentração de $40 \%$ lesou metade da população celular no ensaio, indicando, portanto, citotoxicidade. $\mathrm{O}$ controle negativo mostrou curva de viabilidade celular acima da linha do $\mathrm{IC}_{50}$, ou seja, comportamento não tóxico. Os controles positivo e negativo são utilizados para verificar o desempenho do método.

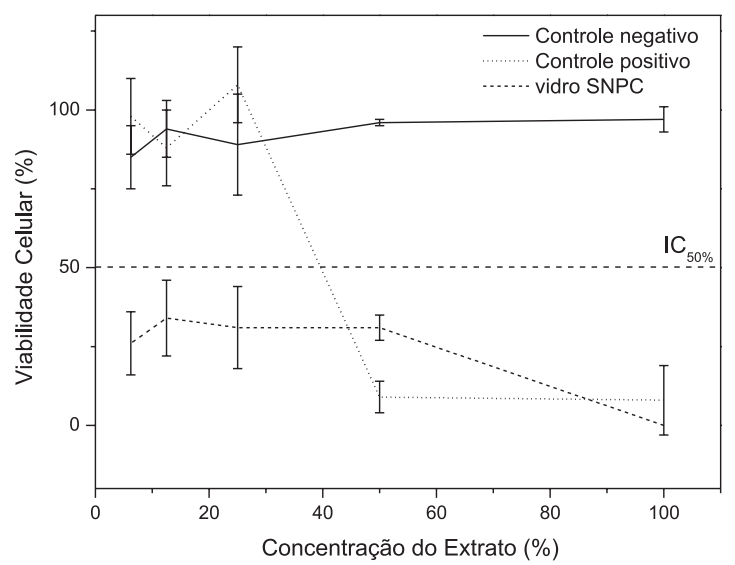

Figura 3. Curvas de viabilidade celular do ensaio de citotoxicidade do pó do vidro SNCP

A curva de viabilidade celular da vitrocerâmica celular preparada pelo método da réplica com o vidro SNCP aquecido a $665^{\circ} \mathrm{C}$, na forma de pó, é mostrada na Figura 4. A amostra de vitrocerâmica celular foi previamente moída até atingir um tamanho de partícula de aproximadamente $45 \mu \mathrm{m}$. Essa amostra apresentou $\mathrm{IC}_{50}$ igual a 28 , ou seja, o extrato dessa amostra na concentração de $28 \%$ lesou metade da população celular no ensaio, indicando, portanto, citotoxicidade.

Como a vitrocerâmica celular preparada pelo método da réplica com o vidro SNCP, quando imersa em SBF, apresentou comportamento bioativo, pois ocorreu a formação de camada de HAp na superfície da mesma, foi realizado o ensaio de citotoxicidade dessa vitrocerâmica celular após imersão em SBF durante 28 dias, a fim de verificar se o material recoberto com HAp deixava de ser citotóxico, uma vez que a HAp é comprovadamente não tóxica. Na Figura 5 é mostrada a curva de viabilidade celular da vitrocerâmica recoberta com HAp, na forma de pó. Esta curva cruza a linha do índice de citotoxicidade e o $\mathrm{IC}_{50}$ obtido foi de 80 , ou seja, o extrato desta amostra na concentração de $80 \%$ lesou metade da população celular no ensaio, sendo, portanto, considerada levemente citotóxica, ou seja, teve a sua citotoxicidade bem reduzida.

Sabe-se que o tamanho de partícula pode afetar a reatividade do material, devido ao aumento da área específica de superfície. Dessa forma, foi feito um novo ensaio de citotoxicidade com o vidro SNCP

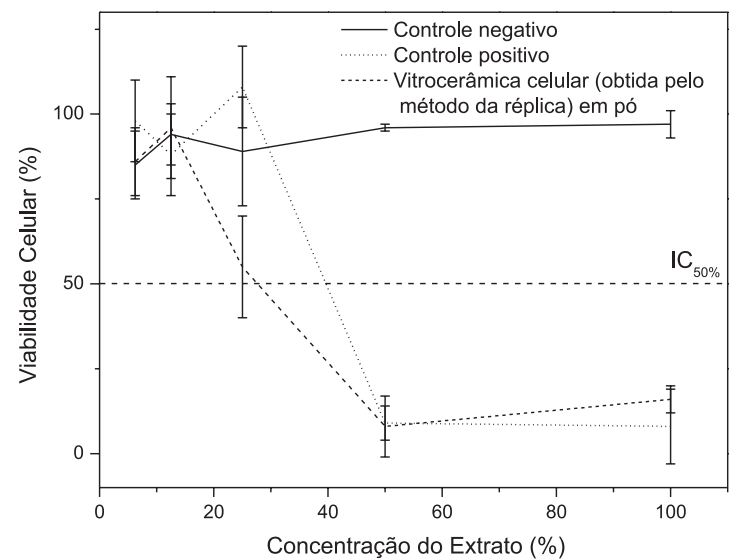

Figura 4. Curvas de viabilidade celular do ensaio de citotoxicidade da vitrocerâmica celular preparada com o vidro SNCP pelo método da réplica, na forma de pó

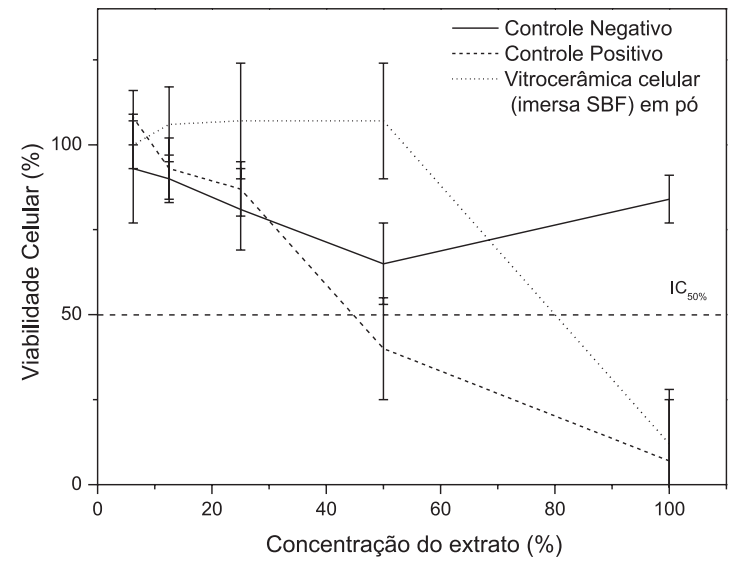

Figura 5. Curvas de viabilidade celular do ensaio de citotoxicidade da vitrocerâmica celular preparada com o vidro SNCP pelo método da réplica, imersa em SBF, na forma de pó

e com a vitrocerâmica celular preparada com o vidro SNCP pelo método da réplica, ambas na forma de cilindro, com $10 \mathrm{~mm}$ de altura e $5 \mathrm{~mm}$ de diâmetro depois de imerso em SBF durante 28 dias. Os resultados dos ensaios de citotoxicidade são mostrados na Figura 6.

De acordo com as curvas de viabilidade celular resultantes do ensaio de citotoxicidade, tanto o vidro SNCP como a vitrocerâmica celular, na forma de cilindro, mostraram um comportamento não citotóxico, semelhante ao controle negativo. Comparando os resultados das amostras na forma de pó e na forma de cilindro, verifica-se que quando o material é fragmentado até a forma de pó, deixa de ser não citotóxico, tanto o vidro SNCP como a vitrocerâmica, apesar de terem apresentado bioatividade antes da fragmentação. Este fato pode ser explicado pela presença da HAp na superfície do cilindro. Como a HAp é um composto não tóxico e biocompatível, confere proteção ao cilindro de vidro e da vitrocerâmica, que demonstraram ser citotóxicos (Figuras 3, 4 e 5).

Segundo Hensten-Pettersen e Jorge et al., ${ }^{32}$ os ensaios in vitro de citotoxicidade podem apresentar alguns desvios, pois quando os testes de citotoxicidade são realizados utilizando extratos obtidos a partir do contato entre as amostras e o meio de cultura, alguns fatores podem influenciar os resultados, como o tempo e a temperatura de extração e a relação entre o volume do meio e a superfície do corpo-de-prova. ${ }^{30,31}$ A norma ISO 10993 sugere como meio para o preparo do extrato água destilada, solução salina ou meio de cultura com ou sem soro, na proporção de 0,5 a $6,0 \mathrm{~cm}^{2}$ de área superficial por $\mathrm{mL}$ 


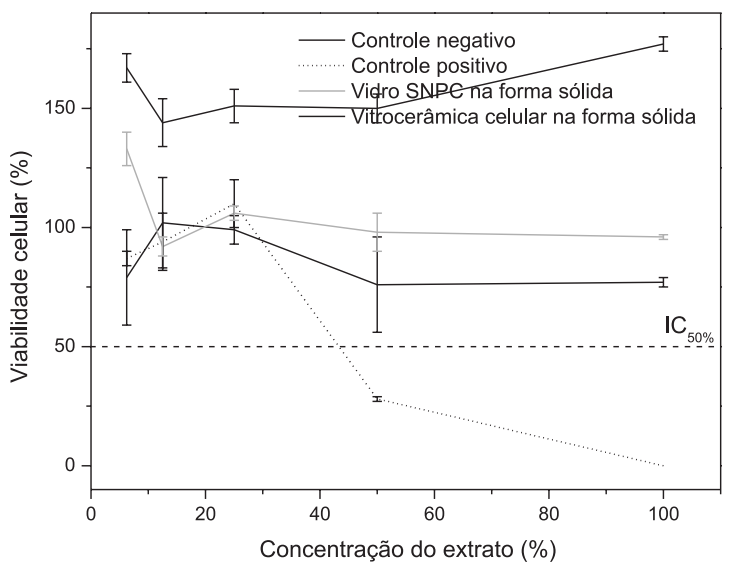

Figura 6. Curvas de viabilidade celular do ensaio de citotoxicidade do vidro SNCP e da vitrocerâmica celular preparada com o vidro SNCP pelo método da réplica, ambas na forma de cilindro e depois de imersas em SBF

do líquido extrator, quando a amostra apresenta geometria definida ou 0,1 a 0,2 g por $\mathrm{mL}$ do meio extrator para material em forma de pó ou geometria não definida. A norma também sugere que o extrato seja preparado a $37^{\circ} \mathrm{C}$, que o tempo de extração não seja menor que 24 h e que as condições sejam as mais próximas possíveis da condição real. Todos estes fatores podem alterar o resultado do ensaio.

Ignatius et al. ${ }^{33}$ reportam que o processamento ao qual o material foi submetido também pode afetar a sua toxicidade, pois pode ocorrer a deposição de algum fragmento diferente do material. Esse fragmento, por sua vez, pode ser facilmente solubilizado durante a obtenção do extrato e causar um aumento da citotoxicidade do material. Para evitar esse tipo de erro, neste trabalho, todas as análises foram feitas em triplicata. É preciso ainda ressaltar que efeitos tóxicos in vitro não significam, necessariamente, toxicidade in vivo. No sistema in vitro, as células estão expostas diretamente ao agente agressor ou a seus produtos e o meio não se renova por cerca de 2 a 3 dias, concentrando possíveis componentes tóxicos. No sistema in vivo, a homeostase proporcionada pelos fluidos pode agir protegendo o organismo, removendo a toxina do sítio de implantação. Além disso, deve-se lembrar que os estudos de citotoxicidade não devem ser os únicos determinantes na avaliação da biocompatibilidade in vitro de um material. O ensaio de citotoxicidade é o primeiro ensaio in vitro de biocompatibilidade e pode ser utilizado para o acompanhamento e correção de processos de obtenção de biomateriais. Outros estudos como, por exemplo, a interação célula-material, são muito importantes para avaliar a adesão e a proliferação das células sobre o material, isto é, citocompatibilidade do material. ${ }^{24}$ Quando o material apresenta leve toxicidade ou não toxicidade, os testes de biocompatibilidade devem ser continuados com ensaios in vivo e os materiais extremamente tóxico devem ser descartados.

Wallace et al. ${ }^{26}$ fazem uma pré-lavagem do biomaterial antes de utilizá-lo em um meio biológico para que o efeito provocado pela variação do pH no meio biológico seja minimizado.

Como esses materiais serão aplicados na forma de vitrocerâmica celular, na qual o material não apresenta comportamento citotóxico, sugere-se o prosseguimento dos demais ensaios in vivo para comprovar a viabilidade de aplicação destes materiais cerâmicos como implante alternativo ao tecido ósseo.

\section{CONCLUSÕES}

Pode-se considerar que o vidro SNCP e a vitrocerâmica celular preparada com o vidro $\mathrm{SNCP}$, pelo método da réplica, são materiais bioativos, pois quando imersos em solução SBF promovem a formação de HAp sobre a sua superfície. No entanto, como vários fatores podem afetar esse tipo de ensaio sugere-se a utilização de diferentes métodos para a obtenção de informações mais abrangentes sobre a bioatividade do material em estudo.

Nos ensaios de citotoxicidade dos materiais na forma de pó, foi verificada a citotoxicidade dos mesmos. Por outro lado, quando foi feito o ensaio da vitrocerâmica celular na forma de pó, depois de imersa em SBF, sua citotoxicidade foi extremamente reduzida e quando os ensaios foram realizados em cilindros não houve indicação de citotoxicidade, evidenciando que toda a área superficial dos cilindros estava protegida pela HAp, comprovadamente não tóxica e biocompatível. O ensaio de citotoxicidade é o primeiro ensaio in vitro de biocompatibilidade e pode ser utilizado para fazer o acompanhamento e correção de processos de obtenção de biomateriais. O ensaio de citotoxicidade da vitrocerâmica celular, obtida pelo método da réplica com o vidro SNCP, após a formação de HAp, indicou um comportamento não citotóxico, ou seja, este material apresenta potencialidade para ser usado como material biocompatível.

\section{AGRADECIMENTOS}

Ao CNPq, pelo suporte financeiro e à Seção de Culturas Celulares do Instituto Adolfo Lutz pelo cultivo celular.

\section{REFERÊNCIAS}

1. Del Guerra Neto, M.; Paiva, A. O.; Costa, N. G.; Rev. Matéria 2005, 10, 31.

2. Andrade, L. A.; Domingues, R. Z.; Quim. Nova 2006, 29, 100.

3. Crovace, M. C.; Dissertação de Mestrado, Universidade Federal de São Carlos, Brasil, 2009.

4. Oliveira, J. M.; Correia, R. N.; Fernandes, M. H.; Biomaterials 1995, 16,849 .

5. Hench, L. L.; Wilson, J.; Introduction to Bioceramics, World Scientific: Singapore, 1993.

6. Furlong, J.; Osborn, J. F.; J. of Bone and Joint Surgery 1991, 73, 741.

7. Resende, C. X.; Dissertação de Mestrado, Universidade Federal do Rio de Janeiro, Brasil, 2007.

8. Tsiomis, A. C.; Dissertação de Mestrado, Universidade Federal de Viçosa, Brasil, 2004.

9. Vogel, M.; Voigt, C.; Gross, U. M.; Muller-Mai, C. M.; Biomaterials 2001, 22, 357.

10. Pantano, C. G.; Clark, A. E.; Hench, L. L.; J. Am. Ceram. Soc. 1974, 57,412 .

11. http://www.unilestemg.br/revistaonline/volumes/01/downloads/ artigo_18.doc, acessada em Janeiro 2010.

12. Kokubo, T.; Kushitani, H.; Sakka, S.; Kitsugi, T.; Yamamuro, T.; J. Biomed. Mater. Res. 1990, 24, 721.

13. Ringer, S.; J. Physiol. (Oxford, U. K.) 1880, 3, 380

14. Tas, A. C.; Biomaterials 2000, 21, 1429.

15. Jalota, S.; Bhaduri, S. B.; Tas, A. C.; Mater. Sci. Eng., C 2008, $28,129$.

16. Juhasz, J. A.; Best, S. M.; Auffret, A. D.; Bonfield, W.; J. Mater. Sci.: Mater. Med. 2008, 19, 1823.

17. Bohner, M.; Lemaitre, J.; Biomaterials 2009, 30, 2175.

18. Ebisawa, Y.; Kokubo, T.; Ohura, K.; Yamamuro, T.; J. Mater. Sci.: Mater. Med. 1990, 1, 239.

19. Ohura, K.; Bohner, M.; Hardouin, P.; Lemaitre, J.; Pasquier, G.; Flautre, B.; J. Biomed. Mater. Res. 1996, 30, 193.

20. Walsh, W. R.; Morberg, P; Yu, Y.; Yang, J. L.; Haggard, W.; Sheath, P. C.; Clin. Orthopaedics and Related Res. 2004, 406, 228.

21. Apelt, D.; Theiss, F.; El-Warrak, A. O.; Zlinszky, K.; BettschartWolfisberger, R.; Bohner, M.; Biomaterials 2004, 25, 1439.

22. ISO 10993-5; Biological evaluation of medical devices, Part 5, Tests for Cytotoxicity: In Vitro Methods, American National Standard, Published by Association for the advancement of Medical instrumentation, 2009. 
23. Rogero, S. O.; Lugão, A. B.; Ikeda, T. I.; Cruz, A. S.; Mater. Res. 2003, $6,317$.

24. Vidal, K. A. L.; Dissertação de Mestrado, Universidade do Grande Rio José de Souza Herdy, Brasil, 2007.

25. Takamori, E. R.; Dissertação de Mestrado, Universidade Estadual de Campinas, Brasil, 2004.

26. Uo, M.; Mizuno, M.; Kuboki, Y.; Makishima, A.; Watari, F.; Biomaterials 1998, 19, 2277.

27. Wallace, K. E.; Hill, R. G.; Pembroke, J. T.; Brown, C. J.; Hatton, P. V.; J. Mater. Sci.: Mater. Med. 1999, 10, 697.
28. Mundstock, K. B.; Moraes, E. G.; Siligardi, C.; Rogero, S. O.; Hotza, D.; Oliveira, A. P. N.; Quim. Nova 2010, 33, 598.

29. ISO FDIS 23317; Implants for surgery - In vitro evaluation for apatiteforming ability of implant materials, International Standard, 2007.

30. Finise, M. R.; Josué, A.; Fávere, V. T.; Laranjeira, M. C. M.; An. Acad. Bras. Cienc. 2001, 73, 525.

31. Hensten-Pettersen, A.; Eur. J. Oral Sci. 2007, 1, 89.

32. Jorge, J. H.; Giampaolo, E. T.; Pavarin, A. C.; Rev. de Odontologia da UNESP 2004, 33, 65.

33. Ignatius, A. A.; Schmidt, C.; Kaspar, D.; Claes, L. E.; J. Biomed. Mater. Res. 2001, 55, 285. 